\title{
Possible Protective Role of Propolis and Nigella Sativa Oil against the Toxic Effects of Chlorpyrifos on the Liver and Testes of Adult Albino Rats
}

\author{
Dalia I.A. Mesallam, Ahmed M. A. Omar, Marwa A. Abass ${ }^{1}$ and Magdy F. Gawish ${ }^{2}$ \\ ${ }^{1}$ Department Forensic Medicine and Clinical Toxicology \\ 2 Department Histology \& Cell Biology \\ Faculty of Medicine, Zagazig University, Al Sharqia, Egypt.
}

\begin{abstract}
Objective: Pesticides are major contaminants of our environment. Chlorpyrifos (CPF), a broad spectrun organophosphate insecticide, is one of the most used organophosphate pesticides in domestic an industrial applications all over the world. This work was undertaken to evaluate the protective effect 0 propolis and nigella sativa oil against the toxic effects of Chlorpyrifos on the liver and testes of adul male albino rats.

Material and methods: Eighty adult male albino rats were used in this study. They were divided into $\varepsilon$ equal groups: Group I (negative control group); Group II (positive control group); Group III gavagec with propolis (400mg/Kg b. w.); Group IV gavaged with nigella sativa oil (100 mg/Kg b.w.); Group I with CPF $6.75 \mathrm{mg} / \mathrm{Kg}$ b. w. / (1/20 of the oral $\mathrm{LD}_{50}$ ); while group VI gavaged with propolis and CPF group VII gavaged with nigella sativa oil and CPF, and group VIII gavaged with both propolis anı nigella sativa oil and CPF in the same previous doses. All treatments were given by oral gavage onc daily for 12 weeks. Blood samples were obtained for assessment of total antioxidant capacity (TAC) Liver and testicular specimens were obtained for assessment of malondialdehyde (MDA) anı histopathological examination by light and electron microscopes.

Results: CPF induced chronic toxic effects in the liver and testes which were evidenced by significan increases in hepatic and testicular MDA and significant decrease in TAC serum levels. These result were confirmed by structural and ultra-structural alterations in liver and testes of CPF treated rats Administration of propolis or nigella sativa alone or in combination ameliorated CPF induced toxi effects, but the most remarkable effects were observed in rats treated with combination of Propolis anı nigella sativa. Conclusion: Combination of propolis and nigella sativa had marked protective effect against CPF-induced toxicity in liver and testes of adult albino rats.
\end{abstract}

Keywords Chlorpyrifos, Liver, Testis, Propolis, Nigella sativa, Oxidative stress.

\section{Introduction}

$\mathrm{C}$ hlorpyrifos (CPF), 0, 0- diethyl 0-(3, 5, 6- tricloro-2pyridinol) phosphorothionate, was first manufactured by Dow Elanco Company in USA and introduced into American market in 1965. It is a broad spectrum chlorinated organophosphate insecticide, utilized extensively in agriculture and non-agricultural settings throughout the world (Michiel et al., 2008).

In non-agricultural settings, CPF is used in many different indoor areas such as homes, offices, schools, hotels, hospitals and restaurants. Also CPF is the active ingredient in commonly used organophosphates insecticides like DURSBAN ${ }^{\circledR}$ and LORSBAN ${ }^{\circledR}$ (Timchalk et al., 2002 and Mitra et al., 2008).
Residual levels of pesticides in Egyptian foods are often higher than those found in developed countries, either because the numbers of skilled technicians available to enforce the laws concerning pesticide usage are inadequate or due to the lack of adequate financial resources (Dogheim, 1996).

Liver is considered one of the target organs of CPF, as it is a site for its metabolism and detoxification (Sams et al., 2004).

Workers and residents who live closer to heavily treated agricultural lands are at risk of their reproductive toxicity (Shittu et al., 2012).

The induction of oxidative stress with subsequent accumulation of lipid peroxidation products is one of the noncholinergic mechanisms implicated in CPF toxicity in different 
organs (Shittu et al., 2012). Reactive oxygen species can elicit detrimental effects on sperm parameters being associated with risk of male infertility (Ji et al., 2012).

Antioxidants can prevent the uncontrolled formation of free radicals or inhibit their reaction with biological sites. Therefore, during oxidative stress, an increase in the exogenous supply of antioxidants improves the capacity of the tissue to cope with high antioxidant demands (Goel et al., 2009).

The nature produces an array of antioxidants to prevent free radical formation or to limit their damaging effects in the cell (Claus et al., 2000). Among those products is propolis (bee glue), a natural product collected by honey bees from various plant sources, which are composed of mainly polyphenols and flavonoids that exhibit antioxidant activity (Khalil, 2006). Also, nigella sativa, commonly known as black cumin, contains thymoquinone that possesses reproducible antioxidant effects through enhancing the oxidant scavenger system (Butt and Sultan, 2010).

It is important to evaluate the potential role of those antioxidants for the protection against oxidative damage and hepatic and reproductive toxicity induced by environmental toxins such as CPF. So the aim of this study is to assess the protective role of propolis and nigella sativa oil against the toxic effects of CPF on the liver and testes of adult albino rats.

\section{Ethical consideration}

our standards of animal care and administration met those required by applicable international laws and regulations. Painless procedures for scarification were performed with appropriate sedation to avoid distress and pain.

\section{Material and methods \\ Material}

\section{1) Chemicals}

a) Chlorpyrifos (CPF)

Chlorpyrifos (99.9\% purity, CAS 2921- 88-2). It was manufactured by Sigma -Aldrich Company, Louis St., USA and purchased from Sigma -Egypt.

\section{b) Propolis:}

It was obtained from Martinez Nieto, S.A., Cartagena, Spain as capsules, each capsule contains $400 \mathrm{mg}$ of purified propolis.

N.B. Composition of propolis can vary depending on location of bees and what trees and flowers they have access to. This can make it difficult for researcher to come to general conclusions about its beneficial effects

\section{c) Nigella Sativa oil:}

It was obtained from PHARCO Pharmaceutics Co., Egypt as capsules, each capsule contains $450 \mathrm{mg}$.

\section{d) Corn oil :}

It was obtained from Sekem Co., Cairo, Egypt (used as a vehicle of CPF, propolis and nigella sativa oil).

\section{2) Animals:}

The study was carried out on 80 adult male albino rats with average weight of (150-200) gm; they were obtained from the Animal House in Faculty of Veterinary, Zagazig University.

\section{Study design}

The rats were divided into 8 groups each of 10 rats:-

Group I (control group)

These rats were left feeding and drinking water to obtain their lab and histopathological parameters as the references comparable values.

\section{Group II (vehicle group)}

These rats were gavaged orally with $1 \mathrm{~mL}$ corn oil (to test the effect of the vehicle) once daily for 12 weeks.

\section{Group III (propolis group)}

These rats were gavaged orally with propolis (400 mg/kg body weight) dissolved in corn oil, once daily for 12 weeks (Bhadauria et al., 2008).

\section{Group IV (nigella sativa oil group)}

These rats were gavaged orally with nigella sativa oil (100 mg/kg) dissolved in corn oil, once daily for 12 weeks (El-Gharieb et al., 2010).

\section{Group V (CPF group)}

These rats were gavaged orally with $\mathrm{CPF}$ at a daily dose of $6.75 \mathrm{mg} / \mathrm{kg}$ (1/20 of the oral LD50 of CPF) dissolved in corn oil for 12 weeks (Goel et al., 2007).

\section{Group VI (CPF and propolis group)}

These rats were gavaged orally with propolis (400 mg/kg body weight) and CPF (6.75 mg/kg body weight) once daily for 12 weeks.

\section{Group VII (CPF and nigella sativa oil group)}

These rats were gavaged orally with nigella sativa oil (100mg/kg body weight) and CPF (6.75 mg/kg body weight) once daily for 12 weeks.

\section{treated group)}

Group VIII (CPF, nigella sativa oil and propolis

These rats were gavaged orally with nigella sativa oil (100mg/kg body weight), propolis $(400 \mathrm{mg} / \mathrm{kg}$ body weight) and CPF (6.75 mg/kg body weight) once daily for 12 weeks.

Methods

At the end of the study (24 hours from the last dose of each substance) the rats of all groups were anesthetized with light ether anesthesia and venous blood samples were obtained from them by means of capillary glass tubes from the retro-orbital venous plexus as described by Nemzek et al. (2001). Liver and testes were dissected and used for assessment of tissue malondialdehyde (MDA) and histopathological examination using both light and electron microscopes.

\section{Biochemical parameters to assess oxidative status:}

a). Determination of the MDA level in the liver and testicular tissues:

The liver and testicular samples were obtained, dissected and put in petri dishes. After the tissues had been washed with physiological saline $(0.9 \% \mathrm{NaCl})$, samples were taken and kept at $-87{ }^{\circ} \mathrm{C}$ until analysis. Then the tissues were homogenized for $5 \mathrm{~min}$ in $50 \mathrm{Mm}$ ice cold KH2PO4 buffer solution ( $\mathrm{pH} 7$ ) $0.5 \mathrm{~g}$ tissue $+5 \mathrm{ml}$ buffer solution using a glass - porcelain homogenizer and then centrifuge at $7000 \mathrm{x} \mathrm{g}$ for $15 \mathrm{~min}$. all processes were carried out at $4^{\circ} \mathrm{C}$. Supernatant was used to determine the MDA concentration (Jain et al., 1989)

\section{b). Total antioxidant capacity (TAC)}

Three $\mathrm{ml}$ of blood were collected from each rat in clean centrifuge tube and incubated at $37^{\circ} \mathrm{C}$ until blood clotted and then centrifuged to separate the serum. The determination of the anti-oxidative capacity is performed by the reaction of antioxidants in the sample with a defined amount of exogenously provide hydrogen peroxide. The antioxidants in the sample eliminate a certain amount of the provided hydrogen peroxide. The residual hydrogen peroxide is assayed colrometrically by enzymatic reaction 
which involves the conversion of 3,5,dichloro -2- hydroxyl benzensulphonate to a colored product (Koracevic et al,. 2001).

\section{Histopathological examination}

\section{A. Light microscopic examination:}

Samples from the liver were fixed in $10 \%$ formalin and samples of the testes were fixed in Bouin's solution. After fixation, tissues were embedded in paraffin blocks as usual and processed for the preparation of $5 \mu$ thick sections. Sections were stained with haematoxylin and eosin and examined by light microscope (Prophet et al., 1992 and Horobin and Bancroft, 1998).

\section{B- Electron microscopic examination:}

The Transmission Electron Microscope (TEM) study was done according to Glauret and Lewis ( 1998). Four to 5 slices of $(1 / 2) \times(1 / 2) \times(1 / 2) \mathrm{cm}$ from liver and testes were immediately fixed in $3 \%$ buffered glutaraldehyde for half an hour. The specimens were further divided to $1 \mathrm{~mm}$ cubes by the aid of dissecting microscope, then dehydrated in ascending grads ethanol, impregnated in a mixture of Propylene oxide/epoxy resin and embedded in oven- dried gelatin capsules. Several sections were cut, 1micron thick using ultramicrotome and glass knives.

The sections were stained with toluidine blue and examined at light microscopy to confirm the presence of pathological changes in haematoxylin and eosin and staining of the sections was carried out using uranyl acetate. The stained sections were examined by TEM in Military Medical Academy, Electron Microscope center, photographes were taken, developed, printed and examined.

\section{Statistical analysis}

Data were analyzed by using Microsoft Excel software (SPSS version 22.0). According to the type of data, the following tests were used to test for significance; differences between multiple means (quantitative variables) were compared by ANOVA test, followed by LSD. P value was set at $<0.05$ for significant results.

\section{RESULTS}

\section{Biochemical Results (oxidative stress parameters)}

As comparing results of MDA level in the hepatic and testicular tissues, and total antioxidant capacity (TAC) in the blood of control and the vehicle groups, there was no significant changes $(\mathrm{P}>0.05)$ among these groups (table 1). So, control group was used as a reference group.

\section{MDA levels in hepatic and testicular tissues}

MDA mean values in CPF group showed a very high significant increase $(\mathrm{p}<0.001)$ as compared to their corresponding values in control, propolis and nigella sativa oil groups. Furthermore, rats given either propolis or nigella sativa oil alone showed a significant decrease $(\mathrm{P}<$ 0.05 , $\mathrm{P}<0.01$ " respectively) in MDA mean values when compared to control group values.

Moreover, Administration of either propolis or nigella sativa oil with CPF resulted in a significant decrease $(\mathrm{p}<0.05)$ in MDA mean values as compared to their corresponding values in CPF treated rats. Furthermore, combined administration of both propolis and nigella sativa oil with CPF resulted in a very high significant decrease $(p<0.001)$ in MDA mean values as compared to their values in CPF group. Comparing MDA mean values of combined propolis, nigella sativa and CPF treated rats with the rest of the studied groups, showed that there was a high significant decrease $(\mathrm{P}<0.01)$ as compared to corresponding mean values of $\mathrm{CPF}$ and propolis treated rats, a significant decrease $(\mathrm{P}<0.05)$ when compared to $\mathrm{CPF}$ and nigella sativa oil treated rats and a non-significant difference $(\mathrm{P}>0.05)$ when compared to control rats (table 2 and figs. $1 \& 2)$.

\section{TAC (Total antioxidant capacity)}

TAC mean values in CPF group showed a very highly significant decrease $(\mathrm{p}<0.001)$ as compared to their corresponding values in control, propolis and nigella sativa oil , groups. Also, it was found that administration of either propolis or nigella sativa oil alone showed a high significant increase in TAC mean values $(\mathrm{P}<0.05, \mathrm{P}<0.01$ respectively) when compared to control group values. Moreover, Administration of either propolis or nigella sativa oil with CPF resulted in a significant increase ( $\mathrm{p}$ $<0.05$ ) in TAC mean values as compared to their corresponding values in CPF treated rats. Furthermore, combined administration of both propolis and nigella sativa oil with CPF resulted in a highly significant increase ( $p$ $<0.001$ ) in TAC mean values as compared to their values in $\mathrm{CPF}$ group. It also resulted in a highly significant increase in TAC mean values as compared to their values in CPF and propolis and CPF and nigella sativa oil groups $(\mathrm{P}<$ 0.01 ) and a non-significant difference when compared to control group mean values ( $\mathrm{P}>0.05$ ) ( table 2 and fig. 3 ).

\section{Histological Results}

\section{Light microscopic examination:}

A-light microscopic examination of the liver:-

- Control group (I), vehicle group (II), propolis group (III) and nigella sativa group (IV):

Plate 1, the liver parenchyma was formed of multiple classic lobules with indistinct boundaries. Each lobule was formed of cords of hepatocytes radiating from central vein. These cords were separated by hepatic sinusoids that were lined by flat endothelial cells (A1). At portal areas, bile ducts were lined by simple cuboid epithelium (A2).

\section{- Chlorpyrifos group (V):}

Plate 1, there was loss of classic hepatic architecture. Most of hepatocytes had darkly stained shrunken nuclei and vacuolated cytoplasm (B1). Cellular infiltrations among hepatocytes were observed (B2). Markedly congested hepatic sinusoids as well as central and portal veins were detected (B3). At portal areas, inflammatory cells with deeply small nuclei were deposited (B4).

\section{- Chlorpyrifos and propolis group (VI):}

Plate 2, they revealed preservation of normal hepatic lobules architecture. Others had disrupted hepatic lobules. Most of hepatocytes had rounded pale nuclei with prominent nucleoli. Few of them contained small deeply stained nuclei. Cytoplasm of hepatocytes was vacuolated (C1). The portal areas contained bile ducts lined with cuboidal epithelium, portal venule and infiltrated cells (C2).

\section{- Chlorpyrifos and nigella sativa group (VII):}

Plate 2, they revealed a preservation of normal hepatic lobular architecture in some lobules. Some hepatocytes had central rounded nuclei with prominent nucleoli and their cytoplasm still had small vacuoles (D1). At portal areas, 
congested blood vessels, bile ducts lined by cuboidal epithelium and a few cellular infiltrations were observed (D2).

\section{- Chlorpyifos, propolis and nigella sativa group (VIII):}

Plate 2, they showed an improvement with minimal affection of few hepatic lobules. This improvement was in the form of preserved lobular architecture, where most of the liver cells began to arrange into hepatic cords that usually radiate from central vein and separated by blood sinusoids, they had rounded vesicular pale nuclei with prominent nucleoli (E1). The cytoplasm was acidophilic and slightly vacuolated especially in the portal areas (E2).

\section{B-Light microscopic examination of the testes:}

- Control group (I), vehicle group (II), propolis group (III) and nigella sativa group (IV):

Plate 3, the testicular parenchyma was formed of closely packed seminiferous tubules and narrow interstitium in between and sperms were observed in their lumen. These tubules were enclosed by a thin connective tissue capsule (A1 \&A2). Seminiferous tubules were lined by stratified germinal epithelium formed of spermatogenic cells (spermatogonia, primary spermatocytes and spermatids) and sertoli cells. These seminiferous tubules were enclosed by a single layer of myoid cell (A3).

- Chlorpyrifos group (V):

Plate 3, the testicular parenchyma was formed of many seminiferous tubules surrounded by relatively thickened capsules. These tubules were lined by disorganized epithelium with marked reduction in thickness of their germinal epithelium (B1\&B2). In most tubules, they were lined by spermatogonia and sertoli cells. Among the seminiferous tubules, interstitial cells, congested blood vessels and homogenous acidophilic exudate were noticed (B3).

- Chlorpyrifos and Propolis group (VI):

Plate 4, the capsular thickness was relatively normal and closely packed seminiferous tubules. Also, homogenous acidophilic exudate in the interstitium was observed (C1). Some of these tubules showed multiple variable germ cells (spermatogonia, primary spermatocytes, and spermatids) and their Lumina were occupied by aggregation of sperms. Others still showed disorganized separated germinal epithelium (vacuolization). (C2).

\section{- Chlorpyrifos and nigella sativa group (VII):}

Plate 4, the capsular thickness was relatively normal and closely packed seminiferous tubules (D1). Most of these tubules showed the germinal epithelium (spermatogonia, primary spermatocytes, and spermatids) and their Lumina were occupied by aggregation of sperms. Some of them showed a slightly separated germinal epithelium. Also, homogenous acidophilic exudate in the interstitium was observed (D2).

- Chlorpyifo, propolis and nigella sativa group (VIII):

Plate 4, they revealed normal capsular thickness and closely packed seminiferous tubules (E1), they lined by stratified germinal epithelium (spermatogonia, primary spermatocytes and spermatids) and their Lumina were occupied by aggregation of sperms. Also, a group of interstitial cells was seen (E2).
II. Electron microscopic examination: A- Electron microscopic examination of the Liver:

- Control group (I), vehicle group (II) Propolis group (III) and nigella sativa group (IV):

Plate 5, they revealed that hepatocytes had euchromatic nuclei and prominent nucleoli. Their cytoplasm contained numerous mitochondria, parallel cisternae of rough endoplasmic reticulum, glycogen granules and few peroxisomes. The bile canaliculi showed short microvilli (A).

\section{- Chlorpyrifos group (V):}

Plate 5, they revealed various morphological changes in hepatocytes; some hepatocyte had smaller electron dense nuclei with much peripheral heterochromatin in comparison with the control one (B1). Their cytoplasm was markedly rarified containing electron lucent lipid droplets of various sizes, vacuoles, peroxisomes and short cisternae of rough endoplasmic reticulum (B2).

\section{- $\quad$ CPF and propolis group (VI):}

Plate 5, they revealed that most of hepatocytes had euchromatic nuclei with prominent nucleoli. The cytoplasm contained numerous mitochondria, glycogen granules, vacuoles and short cisternae of rough endoplasmic reticulum (C).

\section{- $\quad$ CPF and nigella sativa group (VII):}

Plate 5, they revealed that most of hepatocytes had euchromatic nuclei with prominent nucleoli. Their cytoplasm contained numerous mitochondria, few peroxisomes, short cisternae of rough endoplasmic reticulum and few vacuoles (D).

- $\quad \mathrm{CPF}$, propolis and nigella sativa group (VIII):

Plate 5, they revealed that most of hepatocytes had euchromatic nuclei. Their cytoplasm contained numerous mitochondria, smooth endoplasmic reticulum and rough endoplasmic reticulum (E).

\section{B- Electron microscopic examination of the testes:}

- Control group (I), vehicle group (II), propolis group (III) and nigella sativa group (IV):

Plate 6, they showed the spermatogonia (A1). The spermatids had rounded euchromatic nuclei and their cytoplasm was characterized by the presence of peripherally located rounded mitochondria. Some spermatids were seen at the stage of acrosomal formation (A2). Cross sections in mid, principal and end pieces of sperms had a central axoneme. The axonemes of mid pieces were surrounded by fibrous sheath and mitochondrial sheath. The axonemes of principal pieces were surrounded by fibrous sheath only. The axonemes of end pieces were surrounded by cell membrane only (plate 8. Aa \&Ab).

- Chlorpyrifos group (V):

Plate 6, they showed marked reduction of thickness of germinal epithelium in some seminiferous tubules (B1). Spermatids had rounded euchromatic nuclei and peripheral located rounded mitochondria. These spermatids were marked separated by wide intercellular spaces (B2). Other spermatid had heterochromatic nuclei and irregularly distorted mitochondria (B3). Cross sections in mid, principal and end pieces showed markedly distortion of the central axoneme and fibrous and mitochondrial sheaths (plate 8.Ba \&Bb). 
- $\quad$ CPF and propolis group (VI):

Plate 7, they revealed slightly corrugated basement membranes. Both spermatogonia and sertoli cells had euchromatic nuclei, with oval euchromatic nuclei. Some spermatid with euchromatic nucleus and peripherally arranged mitochondria were observed. There was slightly widening of intercellular space between spermatogenic cells were seen (C1 \&C2). Cross section of sperms showed slightly restoration for structure of the mid, principal, and end pieces (plate 8. C).

\section{- $\quad$ CPF and nigella sativa group (VII):}

Plate 7, they revealed regular basement membranes. Both spermatogonia and sertoli cells had euchromatic nuclei, and primary spermatocytes were observed (D1).
Spermatids appeared with euchromatic nuclei and peripherally arranged mitochondria and narrowing of intercellular space were seen (D2). Cross section of sperms showed restoration of the mid, principal, and end pieces (plate 8. D).

- CPF, propolis and nigella sativa group (VIII):

Plate 7, they showed regularly straight basement membranes, Spermatogonia (E1). Also, spermatids appeared with euchromatic nuclei and peripherally arranged mitochondria and markedly narrowing of intercellular space could be seen (E2). Cross section of sperms showed normal restoration of the mid, principal, and end pieces (plate 8. E).

Table (1): student $t$ test for the comparison of hepatic MDA, testicular MDA, and TAC in control and vehicle groups ( $\mathbf{n}=\mathbf{1 0}$ rats / group)

\begin{tabular}{|l|l|l|l|l|}
\hline & \multicolumn{1}{|c|}{ (I) } & \multicolumn{1}{c|}{ (II) } & \multicolumn{1}{|c|}{ t- test } & \multicolumn{1}{|}{ P } \\
\hline MDA (liver)nmol/gm & $94.32 \pm 3.7$ & $95.1 \pm 2.3$ & -0.572 & 0.574 \\
\hline MDA(testis)nmol/gm & $94.3 \pm 2.11$ & $94.75 \pm 0.8$ & -0.642 & 0.529 \\
\hline TAC (mM/L) & $1.4 \pm 0.21$ & $1.4 \pm 0.2$ & 0.045 & 0.965 \\
\hline
\end{tabular}

$\bar{X}=$ arithmetic mean, $S D=$ Standard Deviation, $P>0.05=$ Non-significant difference

Table (2): ANOVA test, one way statistical analysis of hepatic MDA, testicular MDA and TAC in different studied groups ( $\mathrm{n}=10$ rats / group).

\begin{tabular}{|c|c|c|c|c|c|c|c|c|c|}
\hline & $\begin{array}{c}\text { (I) } \\
\overline{\mathrm{X}} \pm \mathrm{SD}\end{array}$ & $\begin{array}{c}\text { (III) } \\
\bar{X} \pm \text { SD }\end{array}$ & $\begin{array}{r}\text { (IV) } \\
\mathrm{X} \pm \mathrm{SD}\end{array}$ & $\begin{array}{r}(\mathrm{V}) \\
\overline{\mathrm{X}} \pm \mathrm{SD}\end{array}$ & $\begin{array}{r}\text { (VI) } \\
\bar{X} \pm \text { SD }\end{array}$ & $\begin{array}{r}\text { (VII) } \\
\bar{X} \pm \text { SD }\end{array}$ & $\begin{array}{r}\text { (VIII) } \\
\bar{X} \pm \text { SD }\end{array}$ & $\mathbf{F}$ & $\mathbf{P}$ \\
\hline MDA (liver) nmol/gm & $94.32 \pm 3$. & $89.8 \pm 4.5$ & $88.5 \pm 2$ & $187.9 \pm 6.2$ & $101.8 \pm 5.2$ & $100.5 \pm 5$ & $95.8 \pm 3.1$ & 605.39 & $<0.00$ \\
\hline MDA (testis) nmol/gm & $94.3 \pm 2.1$ & $92.6 \pm 1.6$ & $92 \pm 1.33$ & $136.7 \pm 2.1$ & $98.2 \pm 1.99$ & $97.2 \pm 1.4$ & $95.6 \pm 0.8$ & 875.32 & $<0.00$ \\
\hline TAC (mM/L) & $1.37 \pm 0.2$ & $1.88 \pm 0.6$ & $2.1 \pm 0.7$ & $0.35 \pm 0.22$ & $0.85 \pm 0.53$ & $0.88 \pm 0.4$ & $1.57 \pm 0.6$ & 13.395 & $<0.00$ \\
\hline
\end{tabular}

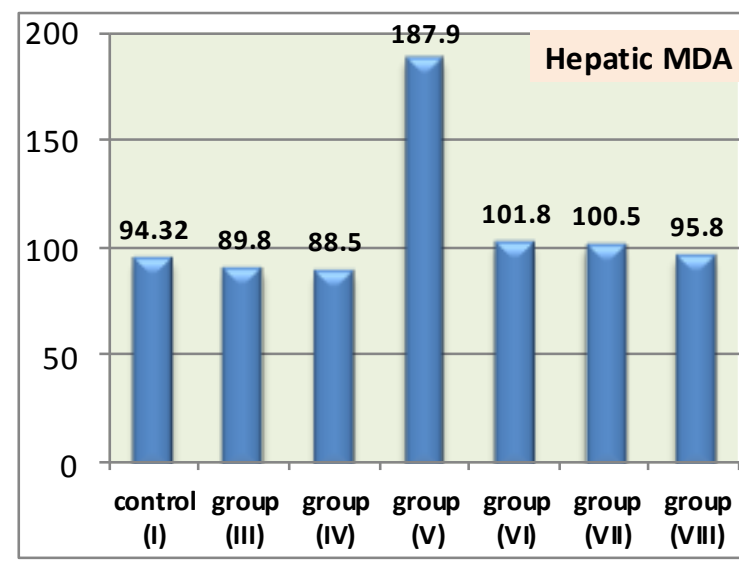

Figure (1): Bar chart showing comparative magnitude of mean values of hepatic MDA (nmol/gm tissue protein) in different studied groups.

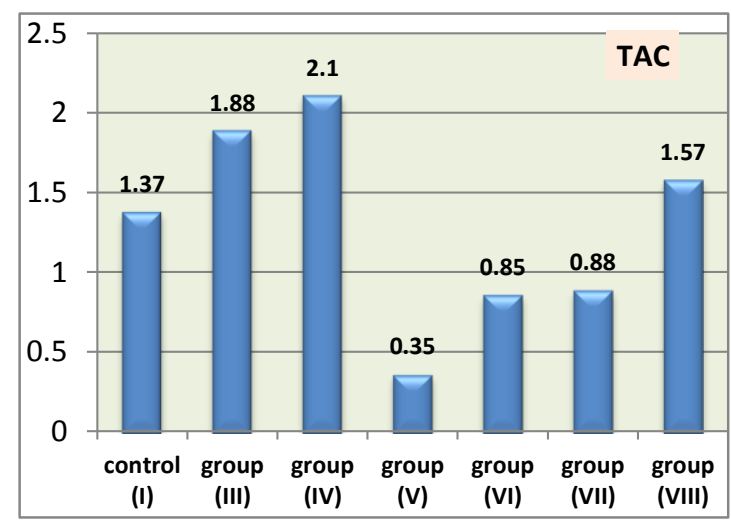

Figure (2): Bar chart showing comparative magnitude of mean values of testicular MDA (nmol/gm tissue protein) in different studied groups. 


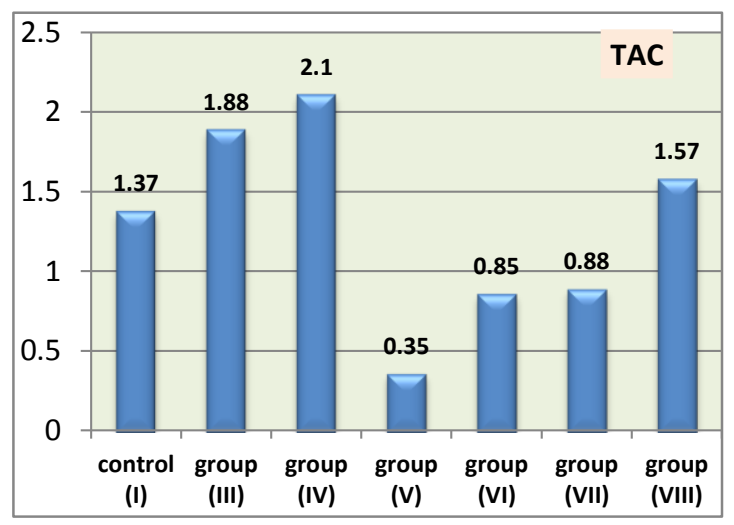

Figure (3): Bar chart showing comparative magnitude of mean values of TAC $(\mathrm{mM} / \mathrm{L})$ in different studied groups.
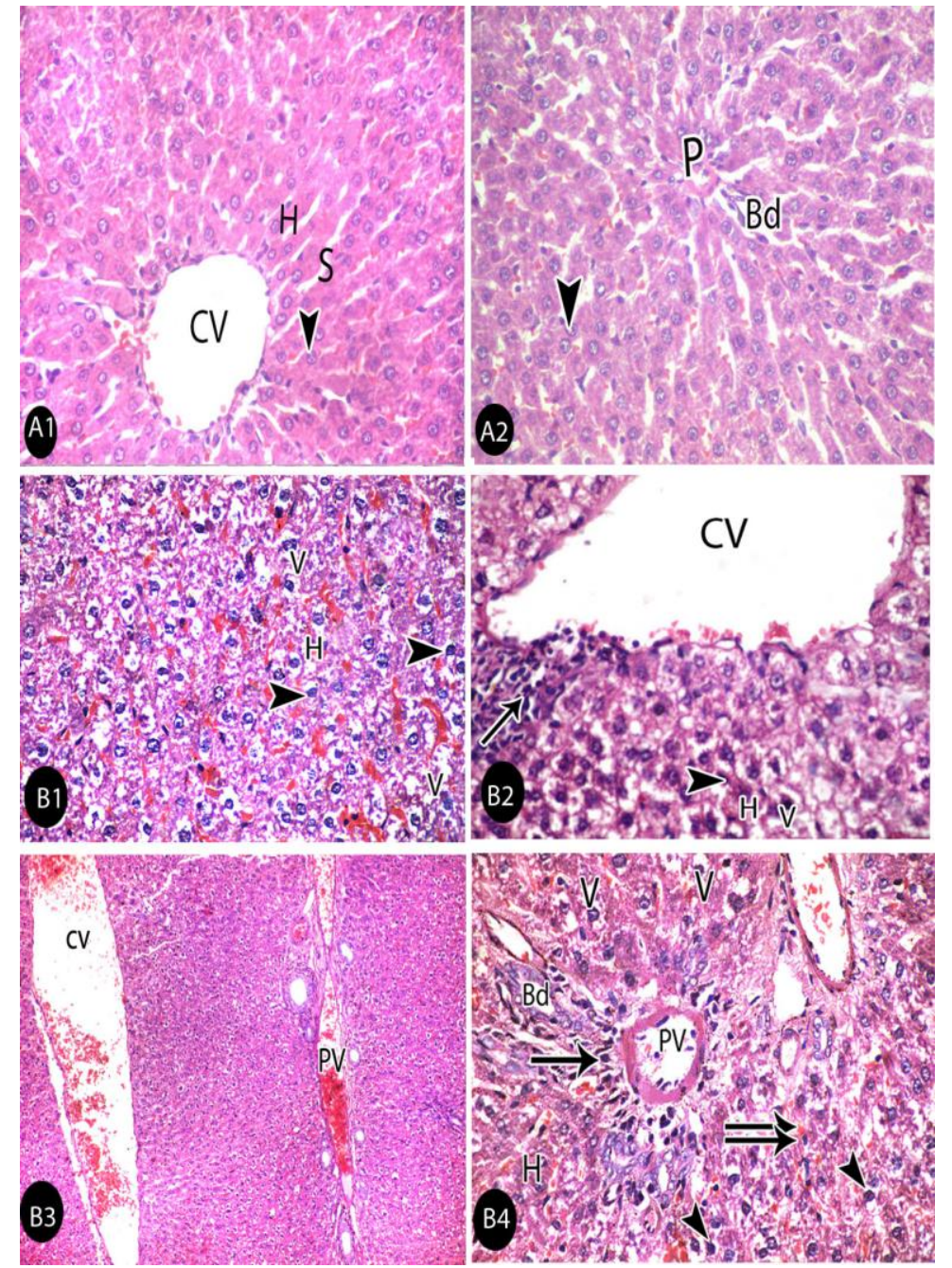

Plate 1. Paraffin sections stained by haematoxylin and eosin (H\&E) for histopathological changes. Liver of control rat showing: (A1) the control histopathological structure of the central vein $(\mathrm{CV})$ and surrounding hepatocytes $(\mathrm{H})$ with central rounded vesicular nuclei (arrow head) and separated by blood sinusoids (S). (x400); (A2) the normal histopathological structure of the portal area contains a branch from portal vein $(P)$ and a bile duct $(B d)(x 400)$. Liver of rat administrated CPF showing: (B1) Loss of lobular architecture and shrunken hepatocytes (H) with cellular vacuolization (V) and apoptotic nuclei (arrow head). (B2) - dilated central vein (CV), and inflammatory cellular infiltration (arrow). (x400). (B3): marked congested dilated central vein $(\mathrm{CV})$ and portal vein $(P V)$. (x100). (B4): cellular infiltration (arrow), apoptotic nuclei (arrow head) and hemorrhage (double arrow) surrounding the congested portal vein $(\mathrm{PV})$ and dilated bile duct $(\mathrm{Bd}) .(\times 400)$. 

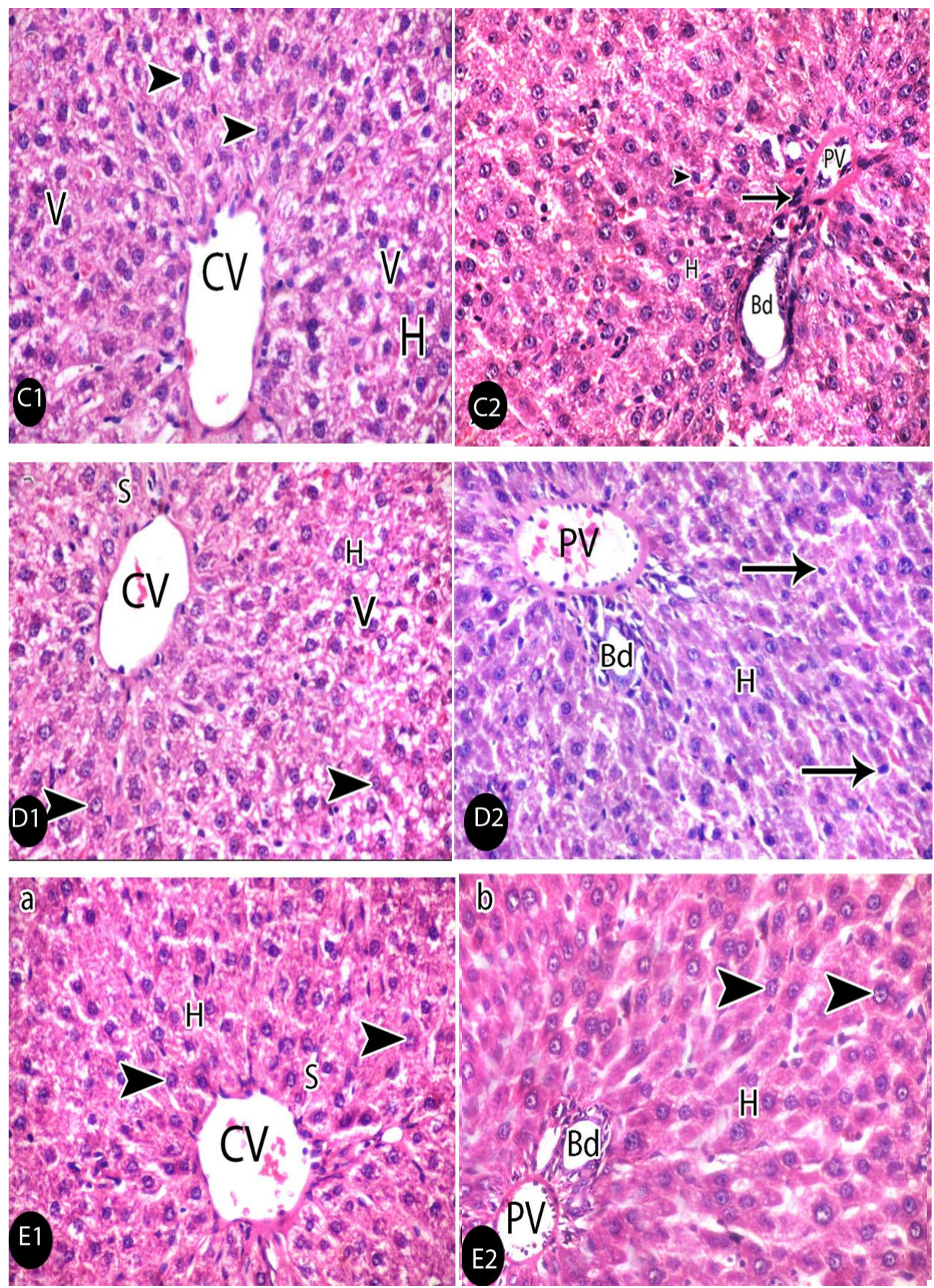

Plate 2: Paraffin sections stained by haematoxylin and eosin (H\&E) for histopathological changes. Liver of rat administrated: CPF + propolis showing (C1) Normal central vein (CV) surrounded with slightly shrunken hepatocytes (H) with pale nuclei (arrow head) with slightly cytoplasm vacuolization (V). (C2): few cellular infiltrations (arrow) in the portal area round the portal venule (PV) are seen. $(x 400)$. Liver of rat adminstrated CPF + nigella sativa showing (D1) hepatocytes (H) have central rounded nuclei (arrow head) with prominent nucleoli, their cytoplasm has small vacuoles (V). (D2) - some apoptotic cells containing darkly stained nuclei (arrow) around the portal area with portal venule (PV), and bile duct (Bd) (x400). $\mathrm{CPF}+$ propolis + nigella sativa showing (E1) - hepatocytes $(\mathrm{H})$ with rounded pale nuclei (arrow head) that are arranged as cords radiating from central vein (CV) and separated by blood sinusoidal spaces (S). (E2) - portal area with portal venule (PV), bile duct (Bd) and hepatocytes (H) with rounded pale nuclei (arrow head). (x400). 


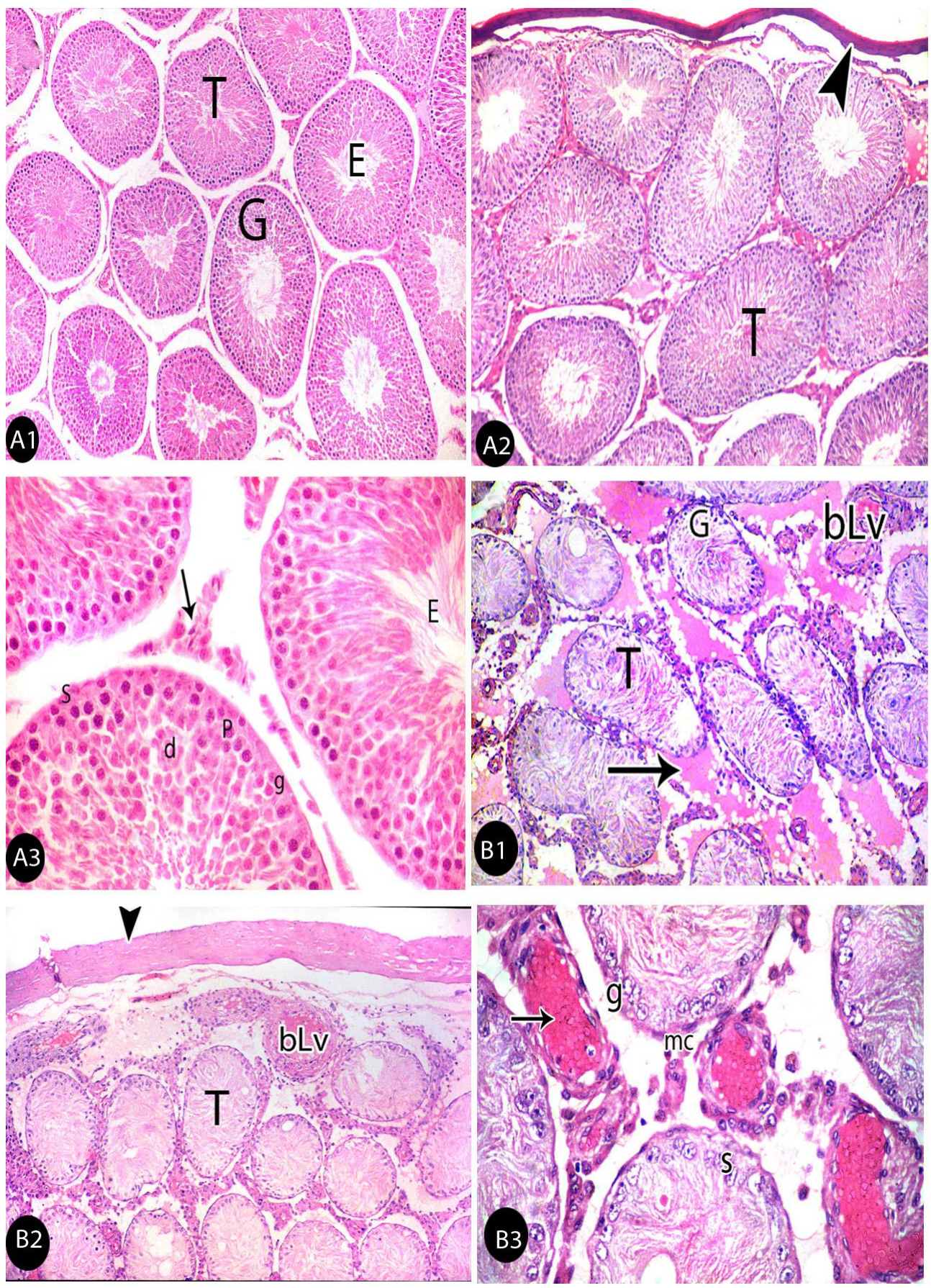

Plate 3. Paraffin sections stained by haematoxylin and eosin (H\&E) for histopathological changes. Testes of control rat showing (A1): Closely packed seminiferous tubules (T), lined by stratified germinal epithelium (G). Their lumina are occupied by aggregation of sperms (E). (A2) - These tubules are enclosed by a thin capsule (arrow head). (X100). (A3): seminiferous tubules are lined by spermatogonia (g), primary spermatocytes (p), spermatids (d), and Sertoli cells (S). Group of interstitial cells (arrow) in the interstitium are seen. (X400). Testes of rat administrated CPF showing (B1): Seminiferous tubules (T) have markedly distorted germinal epithelium (G). Wide interstitum with homogenous acidophilic exudate (arrow) and congested dilated blood vessel (bLv) are observed. (B2) - these tubules are enclosed by thick capsule (arrow head). (X 100). (B3): the seminiferous tubules are surrounded by single layer of myoid cells (mc). The germinal epithelium is formed of single layer of spermatogonia (g) and sertoli cell (S). (X400). 

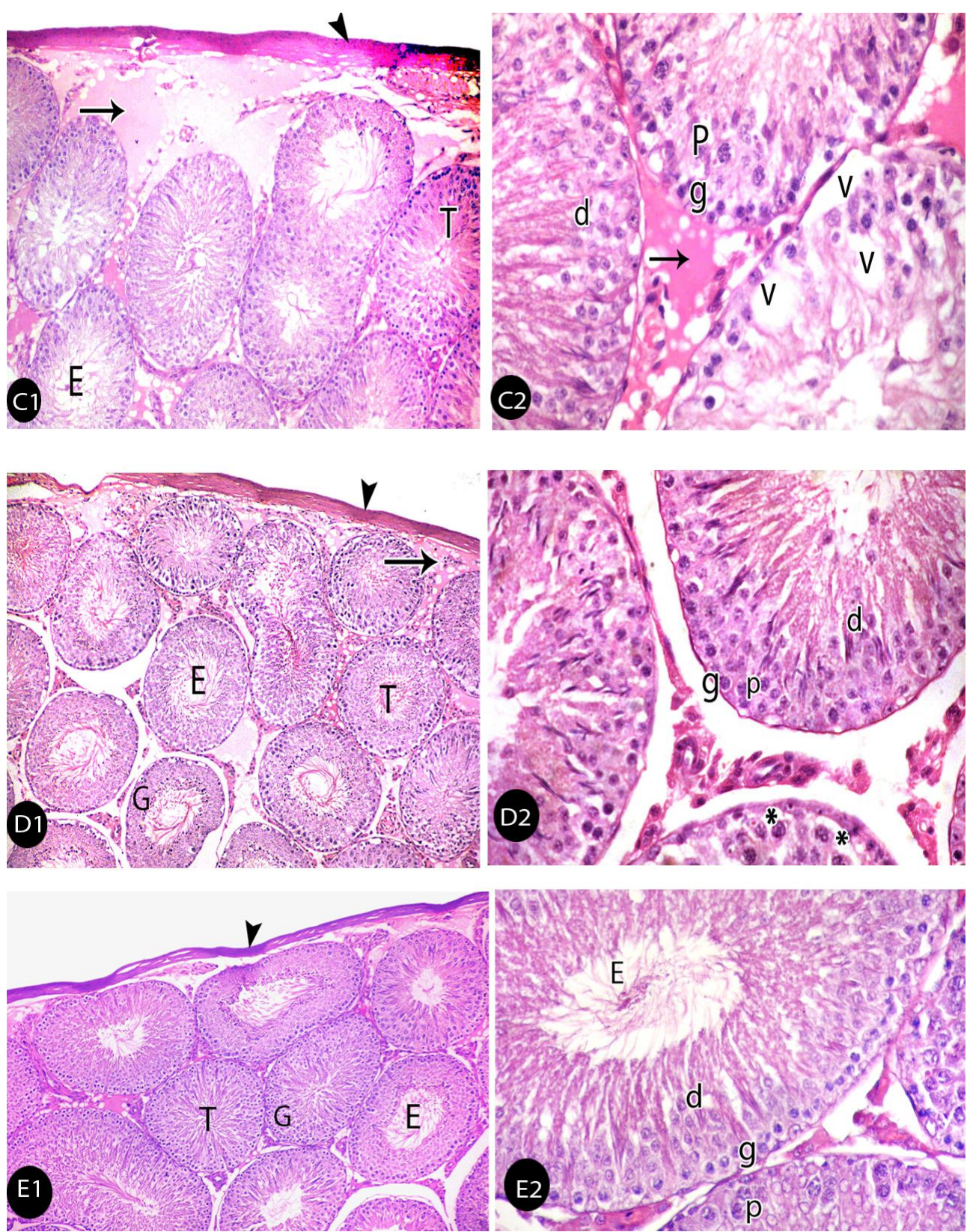

Plate 4. Paraffin sections stained by haematoxylin and eosin (H\&E) for histopathological changes. Testes of rat administrated CPF + propolis showing (C1): a relatively normal capsular thickness (arrow head), closely packed seminiferous tubules (T) with sperms (E) in their lumina. The interstitium shows homogenous acidophilic exudate (arrow) (X 100). (C2): these tubules are lined with stratified germinal epithelium (spermatogonia (g), primary spermatocytes (p), and spermatids (d)). Others still lined with disorganized germinal epithelium (vacuolization) (V). (X400). CPF plus nigella sativa showing (D1): a relatively normal capsular thickness (arrow head), closely packed seminiferous tubules (T), and most of them are lined with full thickness of stratified germinal epithelium (G) with sperms (E) in their lumina. homogenous acidophilic exudate (arrow) in the interstitium is seen (X100). (D2): these tubules still have a slightly separated germinal epithelium (*) (X400). CPF plus nigella sativa + propolis showing (E1): normal capsular thickness (arrow head) and closely packed seminiferous tubules (T) with germinal epithelium (G), and sperms (E) in their lumina (X100). (E2): These tubules are lined by germinal epithelium. (X400). 

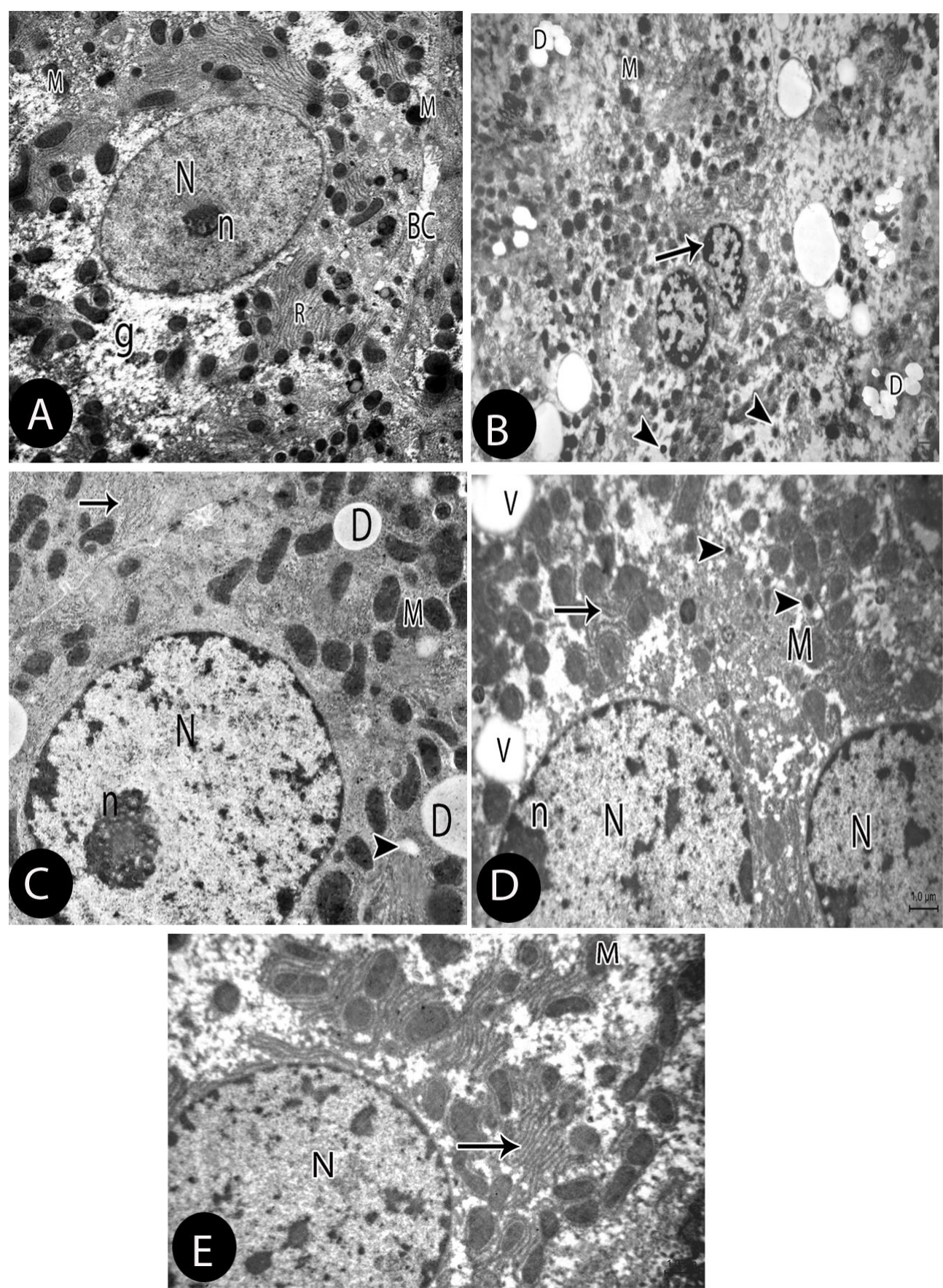

Plate 5. Electron micrographs of hepatic tissue of rats. Control showing (A): a hepatocyte with euchromatic nucleus (N), prominent nucleolus (n), many mitochondria $(M)$, rough endoplasmic reticulum $(\mathrm{R})$ and glycogen granules $(\mathrm{g})$ in their cytoplasm. The bile canilculus with microvilli (BC) is also seen. (X 6000). CPF (B): shows a hepatocyte with apoptotic nucleus (arrow). Its cytoplasm contains peroxisomes (arrow head), numerous fat droplets (D) (x3000). CPF + propolis showing (C): a hepatocyte has euchromatic nucleus $(\mathrm{N})$, numerous mitochondria (M), fat droplets (D), short cisternae of rough endoplasmic reticulum (arrow), and slightly dilated smooth endoplasmic reticulum (arrow head) (x 4000). CPF + nigella sativa showing (D): a hepatocyte with euchromatic nuclei $(\mathrm{N})$, rarified cytoplasm and numerous mitochondria (M), vacuoles (V), few peroxisomes (arrow head) and short cisternae of rough endoplasmic reticulum (arrow). (x 6000). CPF + propolis + nigella sativa showing (E): a hepatocyte with euchromatic nucleus(N), numerous mitochondria (M) and strands of rough endoplasmic reticulum (arrow). (x 6000). 

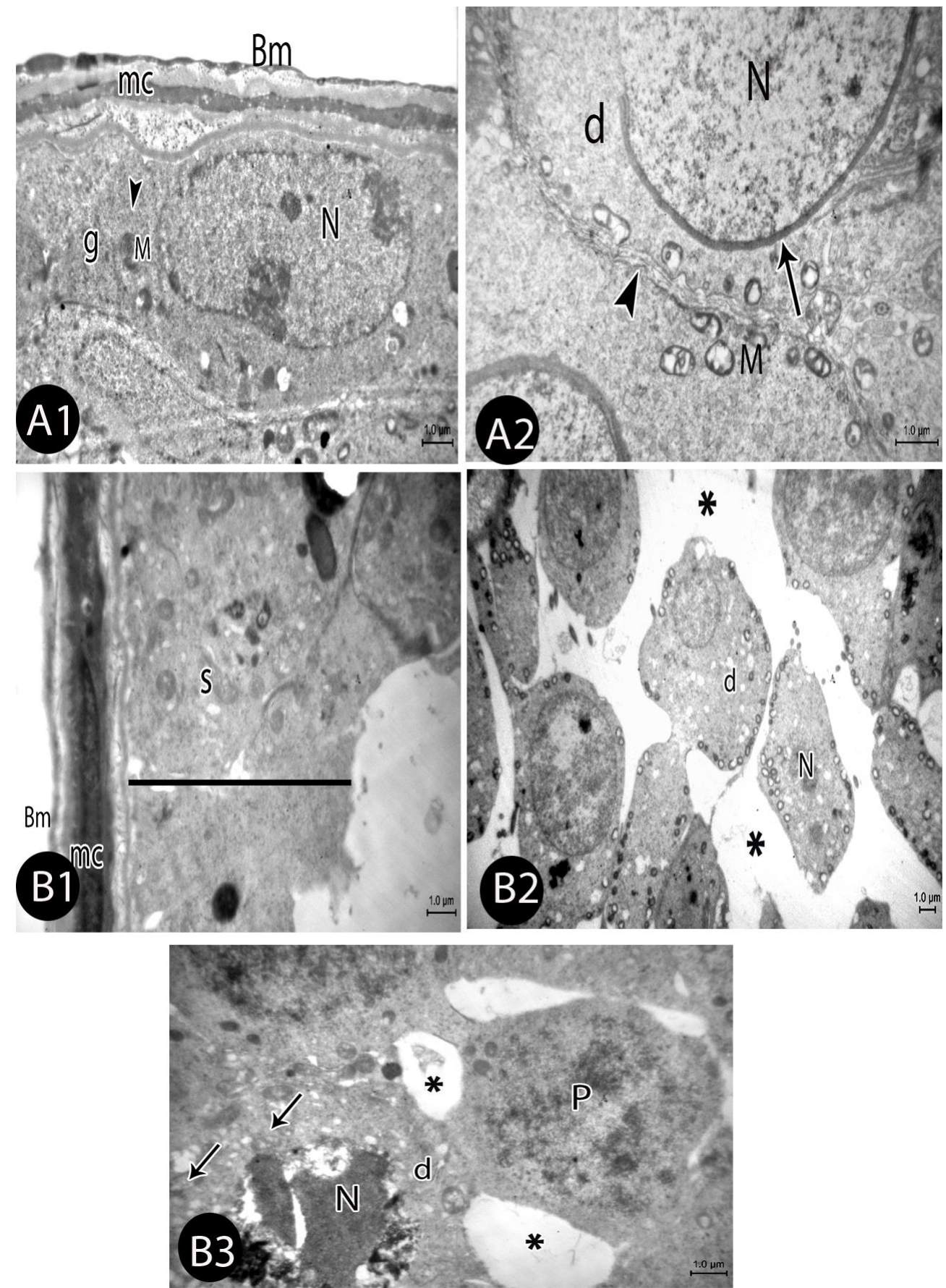

Plate 6. Electron micrographs of testicular tissue of rats. Control showing (A1): basement membrane (Bm), myoid cell $(\mathrm{mc})$, and spermatogonium (g) with euchromatic nucleus (N) and mitochondria (M) and ribosomes (arrow head). (X 6000). (A2): showing spermatids (d) have rounded euchromatic nuclei $(N)$ and their cytoplasm are characterized by the presence of peripherally arranged rounded mitochondria (M), acrosomal cap (arrow), all spermatids are tightly adherent to each other (arrow head). (X 6000). CPF showing (B1): marked reduction of thickness of epithelium (black line) and sertoli cell (S). (X6000).(B2): showing spermatids (d) with marked widening between them $(*)$, one of spermatid with shrunken nucleus (N). (X 3000). (B3): showing primary spermatocyte (P) and spermatid (d) has heterochromatic nucleus (N) and irregularly distorted mitochondria (arrow). (X 6000). 

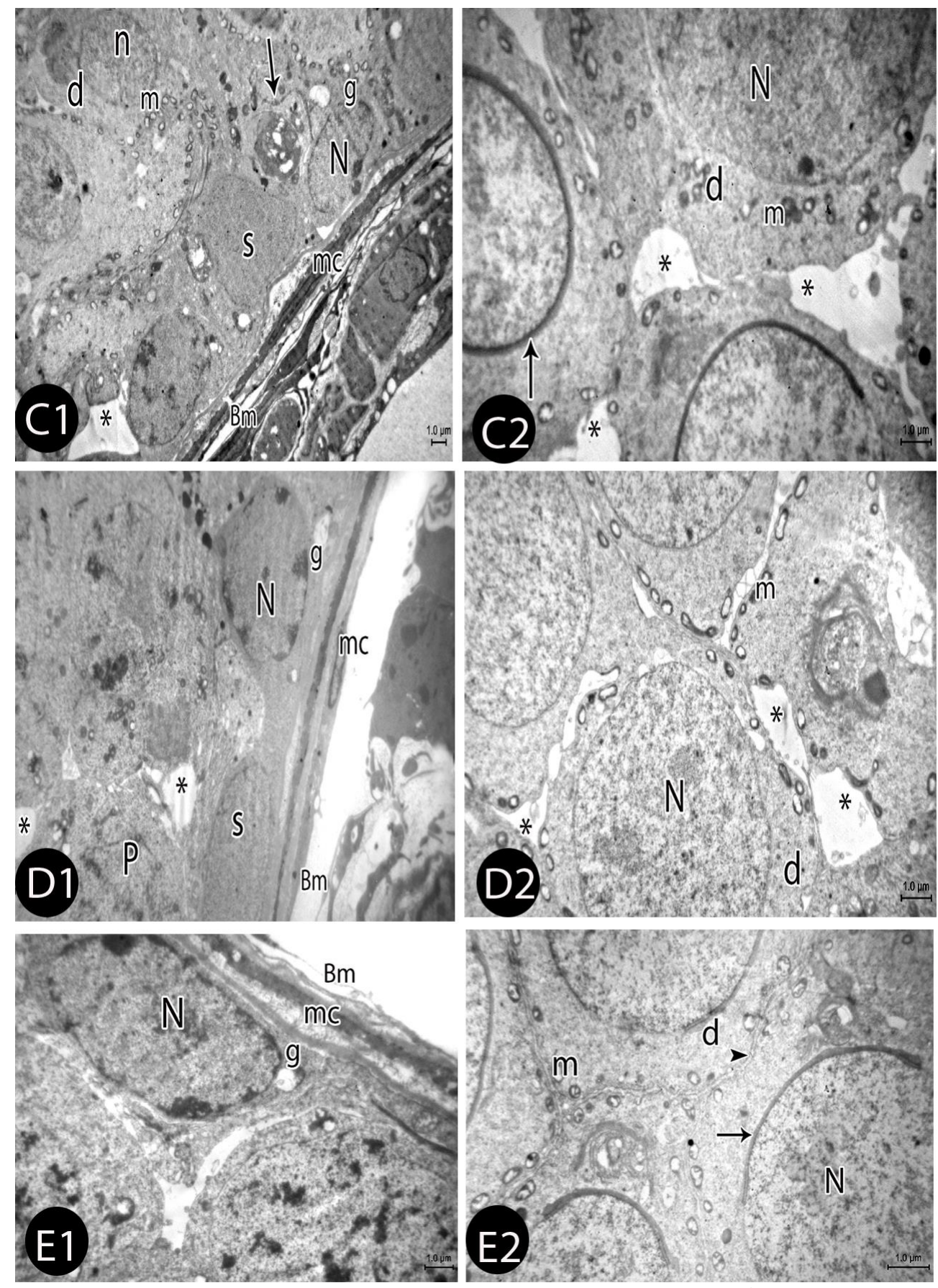

Plate 7. Electron micrographs of testicular tissue of rats. CPF + propolis showing (C1): slightly corrugated basement membrane $(\mathrm{Bm})$, myoid cells $(\mathrm{mc})$, spermatogonium $(\mathrm{g})$ and spermatids (d) with euchromatic nucleus (n). Sertoli cell (S), blood testis barrier (arrow) (X 3000). (C2): restoration of peripherally arranged mitochondria (m) in spermatids and other with acrosomal cap (arrow). Narrowing intercellular spaces between them $(*)$ are seen. $(X$ 6000). CPF + nigella sativa showing (D1): regular basement membrane (Bm), spermatogonium (g), primary spermatocyte (p) and Sertoli cell (S) (X 4000). (D2): spermatids (d) have peripherally arranged mitochondria (m) and narrowing of intercellular space $(*)$. (X6000). CPF + propolis + nigella sativa showing (E1): regularly straight basement membrane $(\mathrm{Bm})$, spermatogonium (g) ( $\mathrm{X}$ 6000). (E2): showing a group of spermatids (d) with acrosomal cap (arrow), and peripherally arranged mitochondria (m). Marked narrowing intercellular spaces between them (arrow head) are seen. (X 8000) 


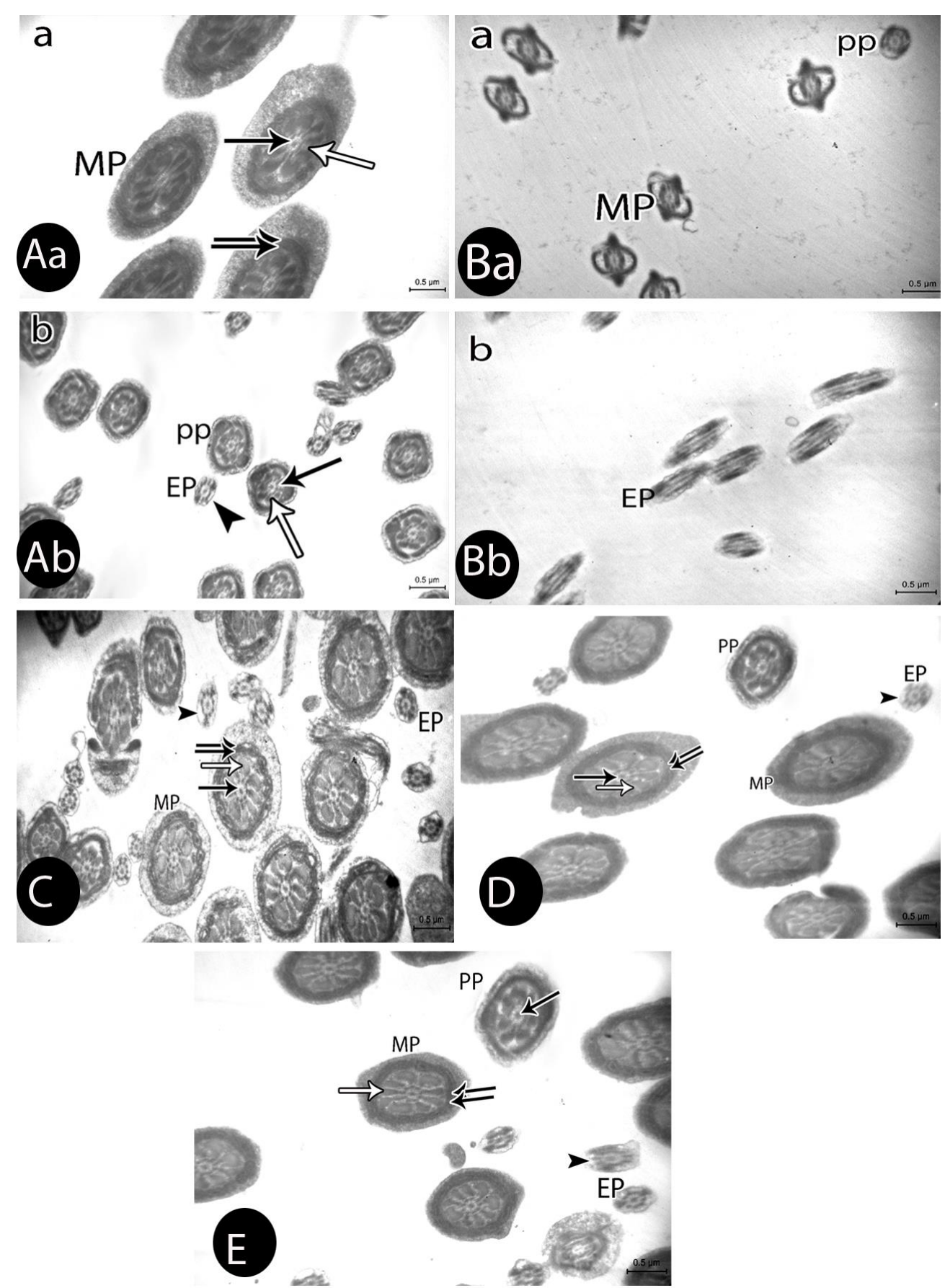

Plate 8. Electron micrographs of the sperm of rats. Control (Aa\&b): Mid pieces (MP) principal pieces (PP), end pieces (EP). CPF (Ba\& b): Marked distortion of the principa (PP), mid (MP) pieces and end pieces (EP). CPF + propolis (C), CPF + nigella sativa (D and $C P F+$ propolis + nigella sativa (E): all show restoration of the mid (MP), principa (PP), and end (EP) pieces. Central axoneme (black arrow), fibrous sheath (white arrow and mitochondrial sheath (double arrow) and cell membrane (arrow head) are seen. ( $X$ 15000)

\section{Discussion}

Chlorpyrifos (CPF) is an extensively used organophosphorus pesticide having many uses in urban and agricultural crop pest control (Eaton et al., 2008).

In our study, there was a highly significant increase in hepatic and testicular MDA and decrease in TAC mean values in CPF group as compared to their corresponding values in control group. Administration of either propolis or nigella sativa alone in CPF treated rats resulted in incomplete restoration of the mean values of
MDA and TAC, as these mean values still were significantly different compared to those of control group.

Furthermore, combined administration of both propolis and nigella sativa oil with CPF resulted in a highly significant decrease in hepatic and testicular MDA and increase in TAC mean values as compared to their values in CPF group, a significant difference in hepatic and testicular MDA mean values as compared to corresponding values of CPF and propolis group and CPF and nigella 
sativa oil group and a non-significant difference when compared to control group.

Malondialdehyde (MDA), a major oxidation product of poly-unsaturated fatty acids, has been considered to be the most significant indicator of membrane lipid peroxidation (LPO) resulted from the interaction of reactive oxygen species (ROS) with cellular membranes (Demir et al., 2011).

Total antioxidant capacity (TAC) represents the cumulative effects of all antioxidants either enzymatic or non-enzymatic existing in plasma, body fluids and tissues. So, it offers more relevant biological information when compared to that attained by the measurement of individual components (Koracevic et al., 2001).

Our results were supported by Verma et al. (2007). They reported that CPF produced oxidative stress resulting in accumulation of lipid peroxidation products in different organs of rats. Moreover, Mansour and Mossa (2010) revealed that CPF treatment caused significant increase in hepatic MDA level and decrease in the activities of rats' plasma superoxide dismutase (SOD) and glutathione s transferase (GST). Additionally, Kalender et al. (2012) and Shittu et al. (2012) reported that CPFtreatment caused an increase in testicular MDA level of rats, which might be due to lipid peroxidation effects of CPF.

The results of the present study were in agreement with Newairy and abdou (2013), they reported ameliorative effects of propolis in CPF-induced increased in hepatic MDA. Jasprica et al. (2007) stated that propolis caused a significant decrease in the MDA level and increase the antioxidant enzymes activities, as it can hinder membrane LPO and free radical formation due to its free radical scavenging ability. Fuliang et al. (2005) showed that propolis elevates glutathione peroxidase (GPx), SOD, GST and catalase (CAT) activities. Therefore, the flavonoids of the propolis can increase the activities of the antioxidant enzymes and reduce the levels of the reactive oxygen species (ROS).

Kanbura et al. (2009) reported that there was a decrease in the hepatic MDA levels and an increase in the antioxidant enzyme parameters in serum SOD, CAT, and GPX of rats on administration of propolis with a similar organophosphorus insecticides (propetamphos). The same results were reported by Newairy et al. (2009) in rats treated with propolis and aluminium chloride. Moreover, Diab et al. (2012) recorded a significant decrease in hepatic MDA levels in rats when received propolis with CPF.

Additionally, El-Mazoudy et al. (2011a) and Attia et al. (2012) reported a significant decrease in the levels of testicular MDA and increase in GPx, GST and CAT on treatment of the rats with propolis with CPF.

The biological and antioxidant effects exhibited by propolis could be related to an overall effect of the phenolic compounds present in propolis (flavonol galangin; hydroxycinnamic acids, caffeic acid, p-cumaric acid, ferulic acid and caffeic acid phenethyl ester) (

Russo et al., 2006). Lipid peroxidation inhibition and scavenging $\mathrm{OH} \cdot$ radicals in the deoxyribose assay were also reported by Marquele et al. (2005).

Furthermore, EI-Gharieb et al (2008) reported an amelioration of hepatic MDA induced by malathion in rats on combined treatment with nigella sativa oil for 60 days. Similarly, Ilhan and Seckin (2005) and Kanter et al. (2005) reported that nigella sativa oil decreased the elevated hepatic MDA and increased the lowered GPx and SOD concentrations in $\mathrm{CCL}_{4}$-induced rat hepatotoxicity. The protection was suggested to be related to the ability of thymoquinone (TQ) component of nigella sativa to inhibit lipid peroxidation.

In addition, Shehab et al. (2014) reported a significant decrease of testicular MDA and increase of CAT, GPx, and SOD, the total GSH concentrations after receiving supplementation with nigella sativa oil for 12 weeks in rats intoxicated with colchicine.

Likewise, Mosbah et al. (2014) recorded a significant decrease MDA and increase in GSH, GPx, CAT, SOD, and GST in testes on administration of nigella sativa oil with CPF.

It appears also that TQ (thymoquinone) in turn exhibits cerebral, renal, liver, and cardiac protective effect against many xenobiotics through its antioxidant action and ability to improve antioxidant activities in animals (Gaskill et al., 2005 and Mohamadin et al., 2010).

Gultekin et al. (2001), Shadnia et al. (2007) and Cemek et al. (2010) reported that, the coadministration of multiple antioxidants is more beneficial in reducing toxic effects of organophosphorus insecticides. These studies supported the results of the current study in which the improvement in hepatic and testicular MDA and in TAC levels was observed in the mean values of CPF intoxicated rats when co-administrated with both propolis and nigella sativa oil was more significant than those observed in CPF intoxicated rats when treated with either propolis or nigella sativa alone.

Disturbed oxidative stress biomarkers of the present study further supported by the following histopathological results. In the present study CPF induced several histopathological alterations in the liver and testes.

Tripathi and Srivastav (2010) and Newairy and Abdou (2013) found similar findings. They observed that exposure to CPF induced histopathological alterations in liver; there were degeneration of hepatocytes, dilatation and vascular congestion in sinusoids, cytoplasmic.

Similar results were observed in another organophosphorus insecticides; diazinon. Kalender et al. (2005) recorded diazinon treatment induced fat vacuoles, swelling of mitochondria and endoplasmic reticulum and loss of chromatin density in nucleus.

The cytoplasmic vacuolization that were observed in hepatocytes of CPF-treated animals reflected a form of cell injury, which cause disturbed membrane function, as these vacuoles developed due to accumulation of ions and water in cytosol and rapidly pass through leaky membranes of cell organelles. Massive accumulation of fluids in the vacuoles may finally lead to cell lysis (Del Monte, 2005).

Other histopathological changes can be explained with some evidences that $\mathrm{CPF}$ has deleterious effects on cytochrome P450 system of hepatocytes or it can also cause changes in membrane transport system of mitochondria in hepatocytes (Nakagawa and Moore, 1999). Interestingly, since mitochondria are the major site of free radical generation and are particularly vulnerable to oxidative stress. So impairment of mitochondrial function leads to cell death via apoptosis and 
necrosis, as it will produce more ROS, a feed-forward loop is set up whereby ROS-mediated oxidative damage to mitochondria favors more ROS generation, resulting in a vicious cycle (Szeto, 2006). Also, the mitochondria contain a variety of antioxidants which are present on both sides of their membranes in order to minimize ROS induced stress (Rahman, 2007).

In the present study, numerous peroxisomes were detected in liver ultrathin sections of CPF group. Cooper (2000) reported that, peroxisomes originally were defined as organelles that carry out oxidation reactions leading to the production of hydrogen peroxide. Peroxisomes also contain the enzyme catalase, which decomposes hydrogen peroxide either by converting it to water or by using it to oxidize another organic compound. Peroxisomes participate not only in the generation of ROS with grave consequences for cell fate such as degeneration but also in cell rescue from the damaging effects of such radicals. The appearance of these peroxisomes supports the hypothesis that CPF induce oxidative stress in liver cells.

In addition to mitochondrial-induced ROS, accumulation of fatty acids in the cytosol increases oxidation of fatty acids in peroxisomes and the endothelial reticulum (Mohajeri and Abdollahi, 2013).

It is possible that oxidative stress can itself activate the insulin signal cascade; high insulin levels stimulate fatty acids synthesis from glucose and inhibit fatty acids $\beta$-oxidation (Videla, 2008). As a result triglycerides may be incorporated into hepatocytes and appear in the form of lipid droplets (Wilasrusmee et al., 2004).

Furthermore, administration of either propolis or nigella sativa with CPF in the present work showed partial improvement. In accordance with Newairy and Abdou (2013) reported that the hepatic histological changes induced after CPF-treatments were markedly reduced with co-administration of propolis.

The anti-inflammatory effects of propolis are suggested to be due to their powerful antioxidants, capable of scavenging free radicals and significantly increased the activities of the antioxidant enzymes thereby protecting the cell membrane against LPO (Frozza et al., 2013).

Oršolić et al. (2012) strongly suggest that antioxidative action of the propolis is able to attenuate alloxan-induced diabetic hepatotoxicity. Treatment with propolis extracts results in decreased number of vacuolated cells and degree of vacuolization.

Also, these results are supported by El-Gharieb et al. (2008) who reported the protective effects of nigella sativa oil on the malathion induced hepatotoxicity, in chronically exposed workers.

The improvement of hepatic tissue after administration of nigella sativa could be explained by clear antioxidant properties, by increasing antioxidant enzymes activities and decreasing oxidant enzymes activities and decreasing lipid peroxidation, also, by scavenging reactive oxygen species (Bourgou et al., 2012).

Additionally, treatment with nigella sativa could be inducing a significant protection as manifested by attenuation of protein oxidation and rejuvenation of the depleted antioxidants of cellular fraction. These results strengthen the hypothesis that TQ exerts modulatory influence on the antioxidant defense system on being subjected to toxic insult (Zafeer et al., 2012).

The combined administration of propolis and nigella sativa oil with CPF revealed maximal improvement with minimal affection of few hepatic lobules,

The combination effect is explained by Nader et al. (2010) who suggested the potential beneficial effects of both propolis and nigella sativa was through synergetic antioxidant mechanism.

Additionally, microscopic examination of the testes specimens of the rats of CPF treated group, in the present study, revealed different degrees of histopathological changes.

It has been reported that pesticides cause various histopathological and cytopathological changes in the male reproductive system (Sarabia et al., 2009). Organophosphate pesticides can cross the blood-testis barrier and cause the degeneration of the spermatogenic cells in experimental animals. Diazinon, an OP pesticide, induced testicular degeneration in mouse testis (Uzun et al., 2009). Similarly, methyl-parathion caused necrosis and edema in the seminiferous tubules and interstitial tissue in rat testes (Uzunhisarcikli et al., 2007).

The results of the present work are supported by El Mazoudy et al. (2011b), Kalender et al. (2012) and Shittu et al. (2013) who reported that the testes of treated rats by CPF showed necrosis, degeneration, decreasing number of spermatogenic cells in some seminiferous tubules and the lumen of the latter devoid of spermatozoa, separating of cells from basal region of seminiferous tubules and exudate in interstitial tissue of testis.

Also, the above mentioned results coincided with Mosbah et al. (2014) who observed that the histopathological changes in testes on administration of CPF are pronounced by alterations of spermatogenesis with a complete loss of all the stages of germ cells maturation, mild to severe degenerative aspects of seminiferous tubules, and widening of interstitial spaces.

Atef et al. (1995) published data that showed degenerative changes of spermatogonial cells and spermatocytes following dimethoate treatment in the rats. Ultrastructural examination of testes of animals showed marked damage in the cytoplasmic organelles in most cells of the seminiferous tubules.

In parallel, Kniewald et al. (2000) reported disintegration and necrosis of spermatogenic elements in testes of mice under the influence of atrazine.

Mitochondria are the key organelles representing cellular damage (Kalender et al., 2005) and pesticide derived mitochondrial pathologies are well known (Joshi et al., 2003).

Also, El-Gerbed (2013) reported that, the ultrastructural changes in methyl parathion-treated rats, disorganization of the seminiferous epithelium, hypospermatogenesis, could be seen. The germ cells showed nuclear pyknosis preceding degeneration and germ cell loss. Vacuolization and edema in interstitial tissue were also observed.

In the present work, there was a relative improvement in the testicular histoarchitecture on administration of the either propolis or nigella sativa with CPF. 
These results in parallel to El Mazoudy et al. (2011b) who stated that treatment of testis of rats with CPF plus propolis revealed remarkable restoration of the normal picture of seminiferous tubules.

Also, in accordance with these results, Mahran et al. (2011) had been investigating the protective effects of propolis against reproductive toxicity of aluminum chloride in male rats with improvement of histopathological and ultrastructural changes were observed.

Al-Sa'aidi et al. (2009) who reported that coadminstration of nigella sativa with CPF had protective effects against CPF-induced toxicity on the testes.

The obvious improvement in the histological study of spermatogenesis in this study agreed with $\mathrm{Al}$ Helali (2002) and Al - Mayali (2007) results who mentioned that the use of black seed causes a clear improvement of spermatogenesis in the animals treated with nigella sativa.

Also, Hussein et al. (2014) support the results who reported that, nigella sativa reduced the testicular ultrastructure alteration induced by aluminum chloride by inducing an antioxidant defense mechanism.

Additionally, Mousa et al. (2015) found that TQ, which is a natural material extracted from nigella sativa, can ameliorate the damaging effect of cadmium on testicular ultrastructure as it has antioxidant and antiinflammatory enzyme activities.

Combined administration of propolis and nigella sativa oil with CPF revealed maximal improvement.

The combination effect is reported by Demir et al. (2015) who stated in their study that propolis, nigella sativa, and TQ could prevent cataractogenesis in ionizing radiation-induced cataracts in the lenses of rats, wherein both propolis and nigella sativa were found to be more potent.

\section{Conclusion}

Chlorpyrifos induces toxic effects on liver and testes of adult male albino rats, that were manifested by disturbed oxidative stress biomarkers and accompanied by structural and ultrastructural changes of liver and testes. Administration of propolis, nigella sativa, alone or in combination highly ameliorated these effects.

\section{Recommendations}

It is recommended to increase public awareness regarding the health impact of Chlorpyrifos. Encouragement of using propolis and nigella sativa as food supplement to decrease the risk of diseases associated with organphosphorous insecticides. Periodical examination of exposed workers is necessary. Other clinical researches on propolis and nigella sativa are needed.

\section{References}

Al - Mayali H A (2007): Study the effect of using phytase and black seed in minimizing the toxic effect of Cadmium chloride on male rat fertility. $\mathrm{PhD}$ Thesis - Eollage of Education, University of Qadsyia - Iraq.

Al-Helali I A H (2002): The effect of nigella sativa $L$. extract in white male mice fertility and some physiological parameters. MsC Thesis, Collage of Science - Kufa University - Iraq.

Al-Sa'aidi J A A, Al-Khuzai A L D, and Al-Zobaydi N F H (2009): Effect of alcoholic extract of nigella sativa on fertility in male rats. Iraqi J. of Veterinary Sci., 23(2): 123-128.

Atef M, Youssef S A, Ramadan A, et al., (1995): Influence of phoxim on testicular and seminal vesicle organs, testosterone and cholinesterase level and its tissue residues in male rats. Dtsch Tierarztl Wochenschr., 102 (8): 1-5.

Attia A A, ElMazoudy R H, and El-Shenawy N S (2012): Antioxidant role of propolis extract against oxidative damage of testicular tissue induced by insecticide chlorpyrifos in rats. Pesticide Biochem. Physiol., 103: 87-93

Bhadauria M, Nirala S, and Shukla S (2008): Multiple treatment of propolis extract ameliorates carbon tetrachloride induced liver injury in rats. Food and Chem. Toxicol., 45:2703-2712.

Bourgou S, Pichette A, Marzouk B, et al., (2012): Antioxidant, anti-inflammatory, anticancer and antibacterial activities of extracts from nigella sativa (black cumin) plant parts. J. Food. Biochem., 36(5):539-546.

Butt M S and Sultan M T (2010): Nigella sativa: reduces the risk of various maladies: Review. Crit. Rev. Food Sci. Nutr., 50 (7): 654-65.

Cemek M, Buyukben A, Buyukokuroglu M E, et al., (2010): Protective roles of vitamin E (alphatocopherol), selenium and vitamin $\mathrm{E}$ plus selenium in organophosphate toxicity in vivo: A comparative study. Pesticide Biochem. Physiol., 96:113-118.

Claus R, Kinscherf R, Gehrke C, et al., (2000): Antiapoptotic effect of propolis extract and propol on human macrophages exposed to minimally modified low density lipoprotein. Arzneimittelforschung., 50 (4): 373-379.

Cooper G M (2000): Peroxisomes. In: The Cell: A Molecular Approach. $2^{\text {nd }}$ edition. By: Cooper, G.M. (ed.). Sinauer Associates. Bosten Unversity, Ch. 10,pp:85-99.

Del Monte U (2005): Swelling of hepatocytes injured by oxidative stress suggests pathological changes related to macromolecular crowding. Medical Hypothesis, 64:818-825.

Demir E, Taysi S, Behcet A, et al., (2015): The effects of nigella sativa oil, thymoquinone, propolis, and caffeic acid phenethyl ester on radiation-induced cataract. Wien Klin Wochenschr. 2015 Apr 10. [Epub ahead of print].

Demir F, Uzun F G, Durak D, and Kalender Y (2011): Subacute chlorpyrifos-induced oxidative stress in rat erythrocytes and the protective effects of catechin and quercetin. Pest. Biochem. Physiol., 99: 77-81.

Diab A E-A, Abd El-Aziz E-S A, Hendawy A A, et al., (2012): possible ameliorative role of propolis and ginseng against hepatotoxicity of chlorpyrifos and profenofos in male rats. J American Science, 8(8):645-664.

Dogheim S M, Ahmed M M, Takla N S, et al., (1996): Multiple analyses of residues in certain plants of medicinal importance. Bulletin of the Entomological Society of Egypt Economics, 15:157-163. 
Eaton D L, Daroff R B, Autrup J, et al., (2008): Review of the toxicology of chlorpyrifos with an emphasis on human exposure and neurodevelopment. Crit. Rev. Toxicol., 38(12): 1-125.

EI-Gharieb M A, EI-Masry T A, Emara A, et al., (2008): Potential hepatoprotective effects of vitamin E And nigella sativa oil on hepatotxicity induced by chronic exposure.to malathion in human and male albino rats. J. Egypt. Soc. Pharmacol. Exp. Ther., 29(2): 347-368.

El-Gerbed M S A (2013): Histopathological and ultrastructural effects of methyl parathion on rat testis and protection by selenium. J. Appl. Pharmaceut. Sci., 3 (8): S53-S63.

El-Gharieb M A, El-Masry T A, Emara A M, et al., (2010): Potential hepatoprotective effects of vitamin E and Nigella sativa oil on hepatotoxicity induced by chronic exposure to malathion in human and male albino rats. Toxicol. Environ. Chem., 92(2):391407.

El-Mazoudy R H, Abd ElGawad H S, and El-Shenawy N S (2011a): Evaluation of protective effect of propolis against testicular oxidative damage, lipid peroxidation and infertility induced by chlorpyrifos in albino rats, Egypt. J. Exp. Biol. (Zool.), 7(2): 129 - 138.

El-Mazoudy R H, Attia A A, and El-Shenawy N S (2011b): Protective role of propolis against reproductive toxicity of chlorpyrifos in male rats. Pest. Biochem. Physiol., 101: 175-181.

Frozza C O, Garcia C S, and Gambato G (2013): "Chemical characterization, antioxidant and cytotoxic activities of Brazilian red propolis," Food Chem. Toxicol., 52:137-142.

Fuliang H U, Hepburn H R, Xuan H, et al., (2005): "Effects of propolis on blood glucose, blood lipid and free radicals in rats with diabetes mellitus," Pharmacol. Res., 51(2): 147-152.

Gaskill C L, Miller L M, Mattoon J S, et al., (2005): Liver histopathology and liver and serum alanine aminotransferase and alkaline phosphatase activities in epileptic dogs receiving phenobarbital. Vet. Pathol. 42:147-160.

Glauret A M and Lewis P R (1998): An introduction to fixation and embedding procedures and their safe use in the laboratory. In: biological specimen preparation for transmission.Glauret, A.M. (ed.). Portland press, London, Vol.17. Pp:15-20.

Goel A, Dani V, and Dhawan D K (2007): Zinc mediates normalization of hepatic drug metabolizing enzymes in chlorpyrifos-induced toxicity. Toxicol. Letters., 169:26-33.

Goel M, Eraslan G, and Silici S (2009): Antioxidant effect of propolis against exposure to propetamphos in rats. Ecotoxicol. Environ. Safety, 72:900-915.

Gultekin F, Delibas N, Yasar S, et al., (2001): In vivo changes in antioxidant systems and protective role of melatonin and a combination of vitamin $\mathrm{C}$ and vitamin $\mathrm{E}$ on oxidative damage in erythrocytes induced by chlorpyrifos-ethyl in rats, Arch. Toxicol., 75 (2001) 88-96.

Horobin R W and Bancroft J D (1998): Hematoxylin and Eosin as an oversight stain .In: Troubleshooting
Histology Stains. First edition Chapter 22 Churchil Livingston, Pearson Professional limited Press, New York, London, and Madrid Melbourne, Sanfrancisco and Tokyo, 88-93.

Hussein O A T, Elghait A T A, and Ahmed S F (2014): Effect of nigella sativa oil on aluminum chlorideinduced testicular damage in male albino rats: a light and electron microscopic study. Egypt J. Histol., 37:741-755.

İlhan N and Seçkin D (2005): protective effect of nigella sativa seeds on CCL4-induced hepatotoxicity. F.Ü. Sağlık Bil. Dergisi, 19(3): 175-179.

Jain S K, Mcvie R, Duett J, et al., (1989): Erythrocyte membrane lipid peroxidation and glycolylated hemoglobin in diabetes. Diabetes, 38:1539-1543.

Jasprica D, Mornar A, Debeljak Z, et al., (2007): In vivo study of propolis supplementation effects on antioxidative status and red blood cells, J. Ethnopharmacol., 110 548-554.

Ji G, Gu A and Wang Y (2012): Genetic variants in antioxidant genes are associated with sperm DNA damage and risk of male infertility in a Chinese population. Free Radical Biol. Med., 52(4): 775780.

Joshi S C, Mathur R, Gajraj A, et al., (2003): Influence of methyl parathion on reproductive parameters in male rats. Environ. Toxicol. Pharmacol. 14, 9198.

Kalender S, Ogutcu A, Uzunhisarcikli M, et al., (2005): Diazinon-induced hepatotoxicity and protective effects of vitamin $E$ on some biochemical indices and ultrastructural changes. Toxicol., 211: 197206.

Kalender Y, Kaya S, and Durak D (2012): Protective effects of catechin and quercetin on antioxidant status, lipid peroxidation and testishistoarchitecture induced by chlorpyrifos in male rats. Environ. Toxicol. Pharmacol., 33(2): 141148.

Kanbura M, Eraslan G, and Silici S (2009): Antioxidant effect of propolis against exposure to propetamphos in rats. Ecotoxicol. Environ. Saf., 72: 900-915.

Kanter M, Coskun O, and Budancamanak M (2005): Hepatoprotective effects of nigella sativa $\mathrm{L}$ and Urtica dioica L on lipid peroxidation, antioxidant enzyme systems and liver enzymes in carbon tetrachloride-treated rats, World J. Gastroenterol., 11(42): 6684-6688.

Khalil M L (2006): Biological activity of bee propolis in health and disease, Asian Pac. J. Cancer Prev., $7: 22-31$.

Kniewald J, Jakominic M, Tomljenovic A, et al., (2000): Disorders of male rat reproductive tract under the influence of atrazine. Appl. Toxicol., 20(1): 6168.

Koracevic D, Koracevic G, Djordjevic V, Andrejevic S and Cosic V (2001): Method for the measurement of antioxidant activity in human fluids. J. Clinic. Pathol., 54:356-417.

Mahran A A, Ahmed H A, and Ahmed M A (2011): Role of propolis in improving male rat fertility affected 
with aluminum chloride cytotoxicity. Spatula DD., 1(4): 189-198.

Mansour S A and Mossa A-T H (2010): Oxidative damage, biochemical and histopathological alterations in rats exposed to chlorpyrifos and the antioxidant role of zinc. Pesticide Biochemistry and Physiology, 96:14-23.

Marquele F D, Di Mambro V M, Georgetti S R, et al., (2005): Assessment of the antioxidant activities of Brazilian extracts of propolis alone and in topical pharmaceutical formulations. J. Pharmaceut. Biomed., 39(3-4): 455-462.

Michiel A D, Steven J H, Paul J V, et al., (2008): Fate and effects of the insecticide chlorpyrifos in outdoor plankton dominated microcosms in Thailand. Environ. Toxicol. Chem., 27(12): 2530-2538.

Mitra N K, Siong H H, and Nadarajah V D (2008): Evaluation of neurotoxicity of repeated dermal application of chlorpyrifos on hippocampus of adult mice. Ann. Agric. Env. Med., 15: 211-216.

Mohajeri S K and Abdollahi M (2013): Toxic influence of organophosphate, carbamate, and organochlorine pesticides on cellular metabolism of lipids, proteins and carbohydrates: A systematic review. Human Experi. Toxicol., 30(9):1119-1140.

Mohamadin A M, Sheikh B, and Abd El-Aal A A (2010): Protective effects of Nigella sativa oil on propoxur induced toxicity and oxidative stress in rat brain regions. Pest. Biochem. Physiol., 98: 128-134.

Mosbah R, Yousef M I, Maranghi F, et al., (2014): Protective role of nigella sativa oil against reproductive toxicity, hormonal alterations, and oxidative damage induced by chlorpyrifos in male rats. Toxicology and Industrial Health, DOI: 10.1177/0748233714554675,

http://tih.sagepub.com/content/early/2014/11/21/0 $\underline{748233714554675}$.

Mousa A M, Salem M M, and El-Mahalaway A M (2015): Effect of thymoquinone on cadmium-induced toxicity of Leydig cells in adult male albino rats: a histological, immunohistochemical, and biochemical study. Egypt J. Histol., 38:308-316.

Nader M A 1, El-Agamy D S, and Suddek G M (2010): Protective effects of propolis and thymoquinone on development of atherosclerosis in cholesterolfed rabbits. Arch. Pharm. Res., 33(4):637-43.

Nakagawa Y and Moore G (1999): Role of mitochondrial membrane permeability transition in $\mathrm{p}$ hydroxybenzoate ester-induced cytotoxicity in rat hepatocytes. Biochem. Pharmacol., 58:811-816.

Nemzek J A, Bolgos G L, Williams B A, et al., (2001): Differences in normal values for murine white blood cell counts and other hematological parameters based on sampling site. Inflammation Research, Vol. 50: Pp. 523-527.

Newairy A A and Abdou H M (2013): Effect of propolis consumption on hepatotoxicity and brain damage in male rats exposed to chlorpyrifos. African Journal of Biotechnol., 12(33): 5232-5243.

Newairy A A, Salama A F, Hussien H M, et al., (2009): Aluminium induced alterations in biochemical parameters and lipid peroxidation of male rats: protective role of propolis, Food Chem. Toxicol. 47:1093-1098.

Oršolić N, Sirovina D, Končić M Z, et al., (2012): Effect of croatian propolis on diabetic nephropathy and liver toxicity in mice. BMC Complementary and Alternative Medicine, 12:117.

Prophet F, Mills B, and Arringlon J (1992): Laboratory methods in histotechnology, Washington DC:AM Registery pathol, 340.

Rahman K (2007): Studies on free radicals, antioxidants and co-factors. Clinical Interventions in Aging, 2(2): 219-236.

Russo A, Troncoso N, Sanchez F, et al., (2006): Propolis protects human spermatozoa from DNA damage caused by benzo[a]pyrene and exogenous reactive oxygen species, Life Sci., 78:1401-1406.

Sams C, Cocker J and Lennard M S (2004): Biotransformation of chlorpyrifos and diazinon by human liver microsomes and recombinant human cytochrome p450s (CYP). Xeno., 34(10):861873.

Sarabia L, Mauer I, and Bustos-Obregon E (2009): Melatonin prevents damage elicited by the organophosphorous pesticide diazinon on mouse sperm DNA. Ecotoxicology and Environmental Safety, 72: 663-668.

Shadnia S, Dasgar M, Taghikhani S, et al., (2007): Protective effects of alphatocopherol and $\mathrm{N}$ acetylcysteine on diazinon-induced oxidative stress and acetylcholinesterase inhibition in rats. Toxicol. Mech. Methods, 17:109-115.

Shehab G M G, Elshama S S, El-Kenawy A E, et al., (2014): nigella sativa seeds ameliorate the testicular toxicity of colchicine repeated use in adult male albino rats: A biochemical and histopathological Study, J. Biol. Chem. Research, 31 (1): 146-163.

Shittu M, Ambali S F, Ayo J O, et al., (2013): Evaluation of chronic chlorpyrifos-induced reproductive toxicity in male wistar rat: protective effects of vitamin C. J. Exp. Integr. Med., 3(1):23-30.

Shittu M, Ayo J O, Ambali S F, et al., (2012): Chronic Chlorpyrifos-induced oxidative changes in the testes and pituitary gland of wistar rats: Ameliorative effects of vitamin C. Pest. Biochem. Physiol., 102:79-85.

Szeto H H (2006): mitochondria-targeted peptide antioxidants: novel neuroprotective agents. A. A. P. S. J., 8(3):521-531.

Timchalk C, Nolan R J, Mendrala A L, et al., (2002): A physiologically based pharmacokinetic and pharmacodynamic (PBPK/PD) model for the organophosphate insecticide chlorpyrifos in rats and humans. Toxicol. Sci., 66: 34-53.

Tripathi S and Srivastav A K (2010): Liver profile of rats after long-term ingestion of different doses of chlorpyrifos. Pest. Bioch. Physiol., 97:60-65.

Uzun F G, Kalender S, Durak D, et al., (2009): Malathioninduced testicular toxicity in male rats and the protective effect of vitamins $\mathrm{C}$ and E. Food Chem. Toxicol., 47: 1903-1908.

Uzunhisarcikli M, Kalender Y, Dirican K, et al., (2007): Acute, subacute and subchronic administration of 
methyl parathion-induced testicular damage in male rats and protective role of vitamins $\mathrm{C}$ and $\mathrm{E}$. Pest. Biochem. Physiol., 87 (2): 115-122.

Verma R S, Mehta A, and Srivastava N (2007): In vivo chlorpyrifos induced oxidative stress: attenuation by antioxidant vitamins. Pest. Biochem. Physiol., 88: 191-196.

Videla L A (2008): Oxidative stress and insulin resistance as interdependent pathogenic mechanisms in nonalcoholic fatty liver disease associated with obesity. In: Free Radical Pathophysiology.
Alvarez, S. and Evelson, P. (eds.). Kerala, India, Trans-world Research Network, pp:369-385.

Wilasrusmee C, Siritheptawee S, Kanchanapanjapo S, et al., (2004): Ultrasructural changes in cirrhotic and noncirrhotic patient due to hepatectomy. J. of hepato-biliary-pancreatic surgery, 11(4):266-271.

Zafeer M F, Waseem M, Chaudhary S, et al., (2012): Cadmium-induced hepatotoxicity and its abrogation by thymoquinone. J. Biochem. Mol. Toxicol.., 26(5): 199-205.

الملخص العربي

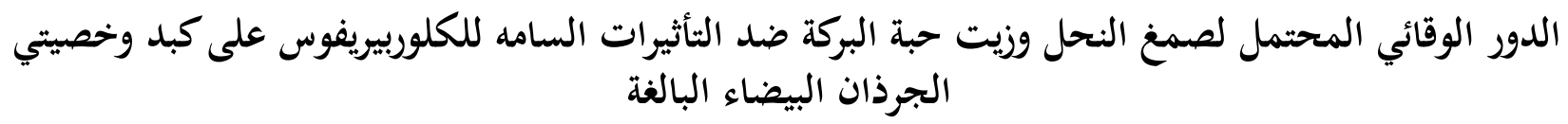

داليا إبراهيم أحمد مسلم و أحمد محمد احمد عمر و مروة أحمد عباس ا و مجدي فتحي جاويشץ

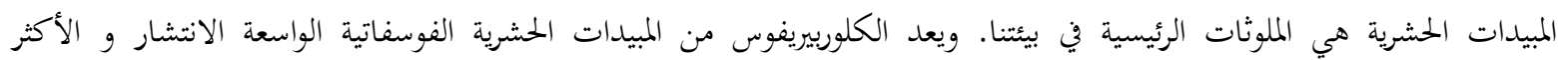

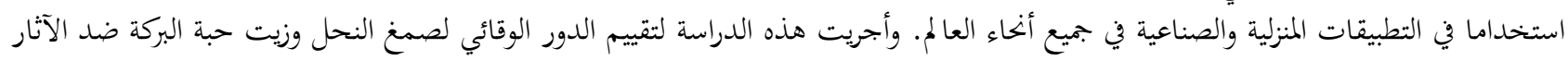

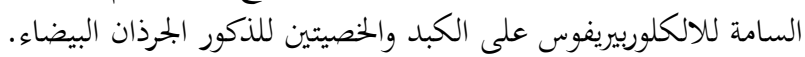

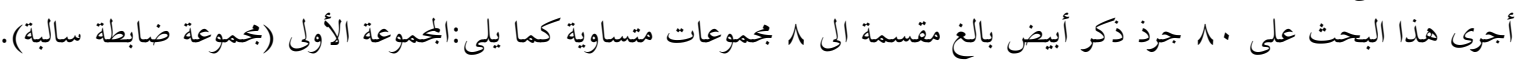

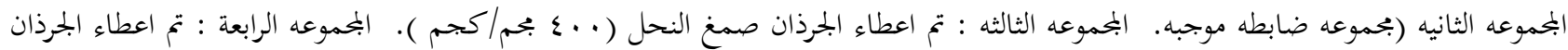

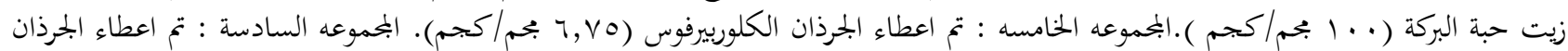

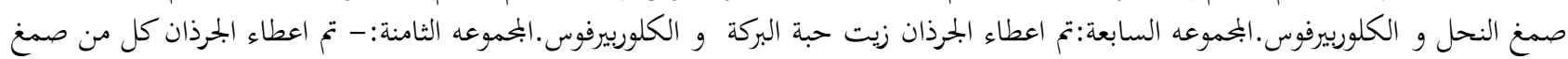

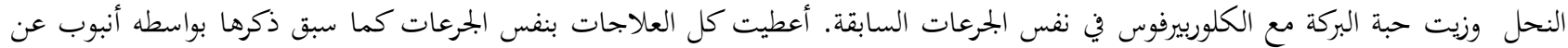

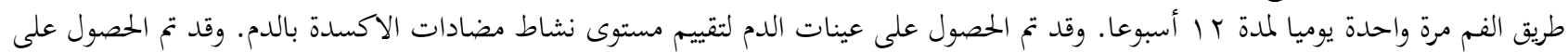

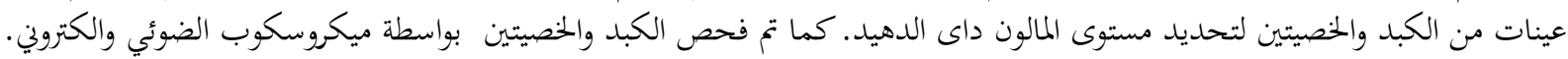

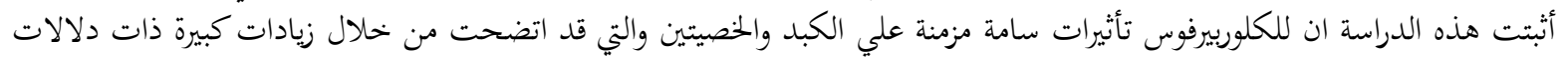

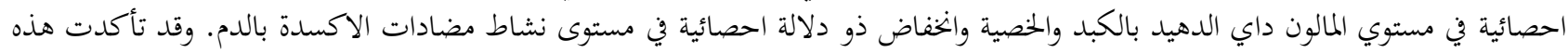

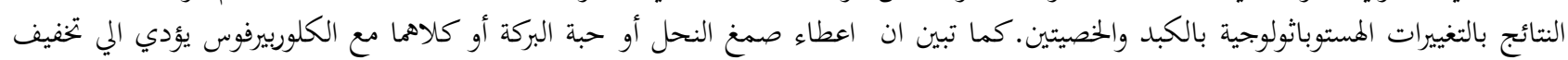

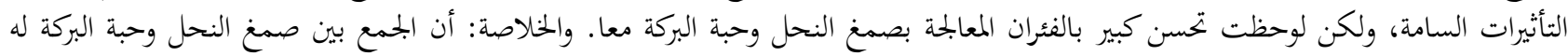

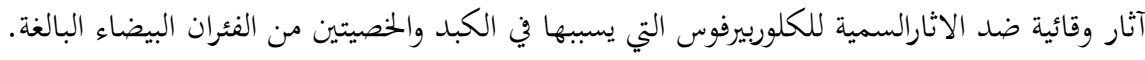

